\title{
ATOMIC HYDROGEN REACTION RATES IN AQUEOUS SOLUTION VIA FREE-INDUCTION DECAY ATTENUATION
}

\author{
David M. Bartels \\ Chemistry Division, Argonne National Laboratory
}

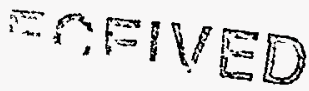

FFR 16 198S

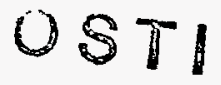

Development of a new pulsed-EPR method - free induction decay attenuation - is providing high-precision data for $\mathrm{H}$-atom reaction rates in water, both for predictive modeling applications and for fundamental theory. Reactions of atomic hydrogen are important in the radiation-induced chemistry of aqueous solutions, contributing to corrosion problems in nuclear reactor cooling systems, production of potentially explosive $\mathrm{H}_{2}$ gas in high-level radioactive waste reservoirs, and the spread of radioactive iodine following the Chernobyl accident. Atomic Energy of Canada, Ltd. and Argonne scientists have undertaken a collaborative effort to investigate fundamental aqueous $\mathrm{H}$-atom chemistry for the purpose of developing predictive models of iodine transport that will be used by the nuclear power industry to enhance plant safety. Reactions of $(H)$ aq with many representative organic and inorganic molecules have already been investigated, including $\mathrm{OH}^{-}, \mathrm{I}^{-}, \mathrm{IO}_{3}^{-}, \mathrm{IO}_{4}^{-}, \mathrm{O}_{2}, \mathrm{CH}_{3} \mathrm{l}$, $\mathrm{CH}_{3} \mathrm{CH}_{2} \mathrm{l}$, methanol, acetone, methyl ethyl ketone, propionaldehyde, and butyraldehyde.

The measurement technique that enables this progress was developed by Dr. David Bartels of the Argonne National Laboratory Chemistry Division. The work would not have been possible without long-term financial support from DOE Division of Chemical Sciences, Office of Basic Energy Sciences. Radiolysis of aqueous solutions with $3 \mathrm{MeV}$ electrons from a Van de Graaff accelerator produces $\mathrm{H}$ atoms in high yield; in the free induction decay method, a powerful $30 \mathrm{~ns}$ microwave pulse is applied to the sample immediately following pulse radiolysis, creating a phase coherence of the $\mathrm{H}$ atom electron spins that is detected in the pulsed-EPR spectrometer as a damped cosine free induction decay (FID). The natural decay time ( $\left.T_{2}\right)$ of the spin coherence is many microseconds, but if a reaction partner for the $H$ atoms is introduced, the FID becomes shorter, revealing the hydrogen reaction rate. 


\title{
ATOMIC HYDROGEN REACTION RATES IN AQUEOUS SOLUTION VIA FREE-INDUCTION DECAY ATTENUATION
}

\author{
David M. Bartels \\ Chemistry Division, Argonne National Laboratory
}

It has been known for many years that reactions of atomic hydrogen are important in the radiation-induced chemistry of aqueous solutions, contributing to corrosion problems in nuclear reactor cooling systems and production of potentially explosive $\mathrm{H}_{2}$ gas in high-level radioactive waste reservoirs. Atomic hydrogen reactions are also extremely important test cases in developing a first principles theoretical understanding of chemical reaction rates in the gas phase and in solution. Recent development of a new method at the Argonne National Laboratory Chemistry Division - free induction decay attenuation - is providing new high-precision data for $\mathrm{H}$-atom reaction rates in water, both for predictive modeling applications and for fundamental theory.

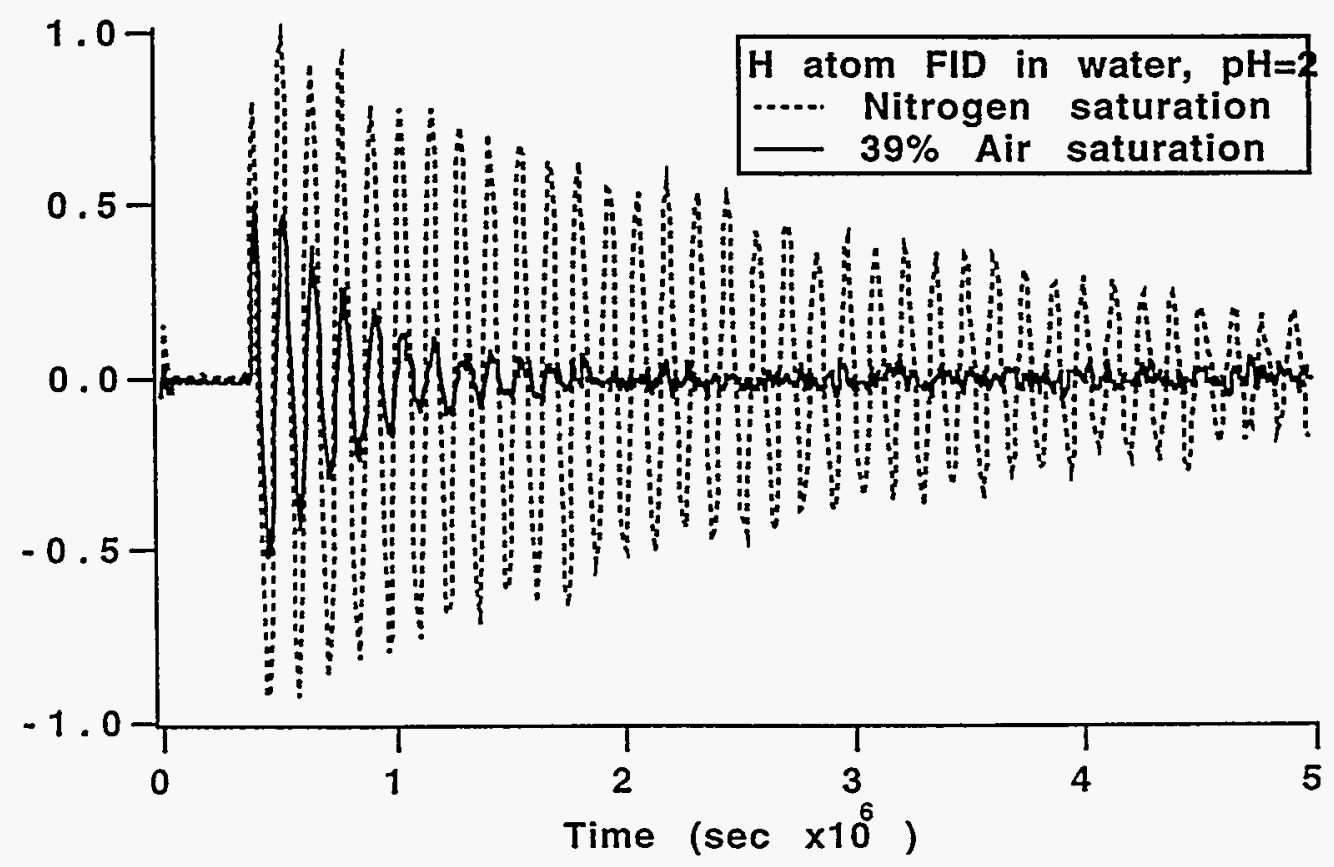

Fig. 1. Typical free induction decays of the $\mathrm{H}$-atom low field $\left(\mathrm{m}_{\mathrm{I}}=+1 / 2\right)$ line immediately following pulse radiolysis of $\mathrm{pH} 2$ aqueous solution. The FID is attenuated in the partially air-saturated solution by the presence of $\mathrm{O}_{2}$. 
The method is designed around a Van de Graaff accelerator that produces short (5-25 ns) pulses of $3 \mathrm{MeV}$ electrons for radiolysis of samples within the cavity of a pulsed electron paramagnetic resonance (EPR) spectrometer. Radiolysis of acidic aqueous solutions produces $\mathrm{H}$ atoms and $\mathrm{OH}$ radicals in high yield; detection of the $\mathrm{H}$ atoms by traditional optical transient absorption is very difficult in water, but they are relatively easy to detect by their distinctive doublet EPR spectrum with its very large hyperfine splitting. In the free induction decay method, a powerful $30 \mathrm{~ns}$ microwave pulse is applied to the sample immediately following pulse radiolysis, creating a phase coherence of the $\mathrm{H}$-atom electron spins that is detected in the EPR spectrometer as a damped cosine free induction decay (FID). The natural decay time $\left(T_{2}\right)$ of the spin coherence is many microseconds. However, if a reaction partner, or scavenger of the $\mathrm{H}$ atoms, is introduced, the chemical reaction introduces a new mechanism for loss of spin coherence. The FID becomes shorter, as illustrated in Fig. 1 with the introduction of oxygen to the sample. A plot of the FID decay rate vs. scavenger concentration, as in Fig. 2, produces a straight line whose slope is the rate constant for the $\mathrm{H}$-atom reaction (pseudo-first-order scavenging kinetics).

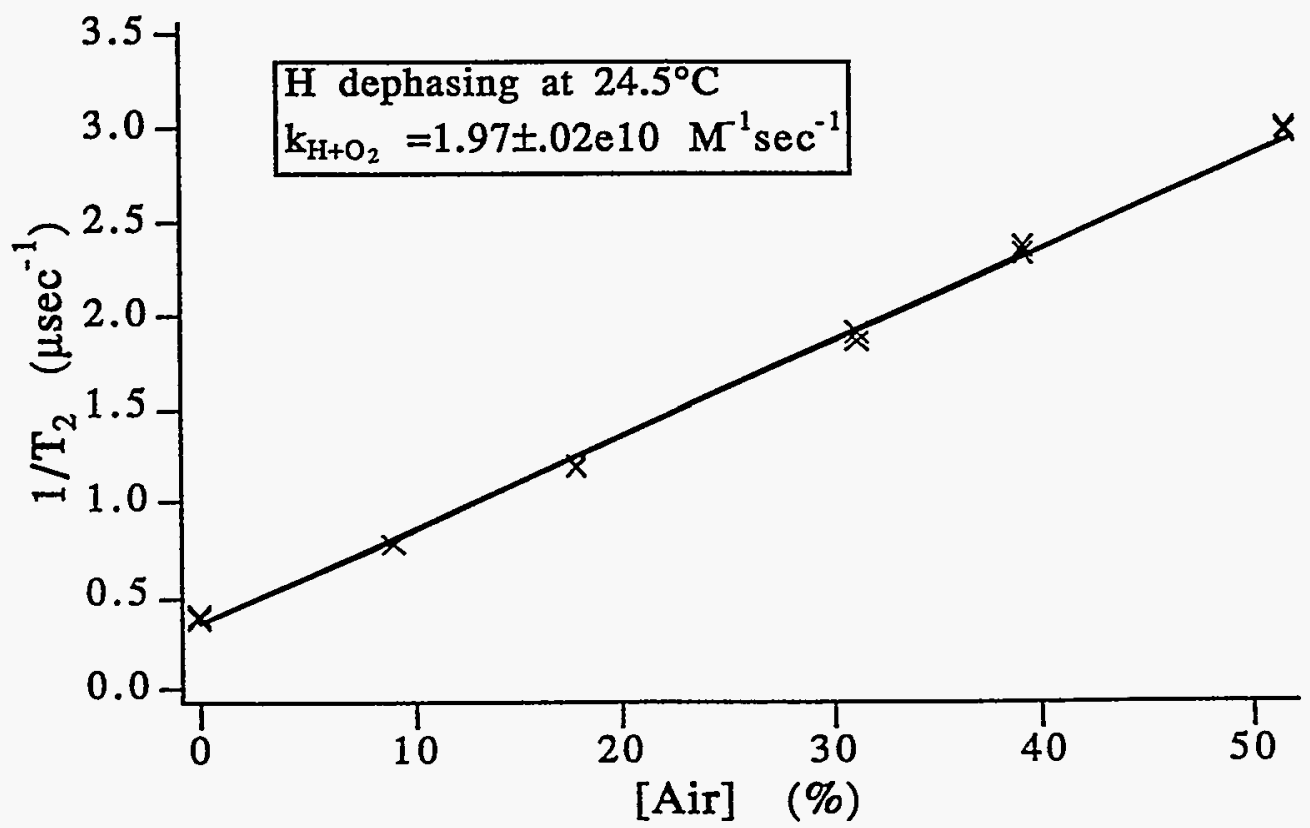

Fig. 2. Pseudo-first order scavenging plot of $\mathrm{H}$-atom dephasing rate vs. \% air in saturating gas at $24.5^{\circ} \mathrm{C}$. 
Among the important systems studied with this technique is the addition of the $\mathrm{H}$ atom to benzene to give the cyclohexadienyl radical. In a mixture of $\mathrm{H}_{2} \mathrm{O}$ and $\mathrm{D}_{2} \mathrm{O}$, addition of both $\mathrm{H}$ atoms and $D$ atoms were studied in the same solution to measure the H/D primary isotope effect (ca. 1.4 ). The average activation energy of $19.1 \mathrm{~kJ} / \mathrm{mole}$ in water is virtually identical to the gas phase value, but the pre-exponential factor is some 54 times larger, and some slight curvature (concave downward) of the Arrhenius plot is visible in the $5-90^{\circ} \mathrm{C}$ temperature range. These properties of the reaction were correlated in a nearly quantitative fashion by application of the transition state theory. It is straightforward to show that the ratio of liquid and (high-pressure) gas phase reaction rates can be given in terms of the free energies of solvation of the reactants and transition state $(\dagger)$, as long as tunneling is not a significant component of the reaction rate:

$$
\mathrm{k}(\mathrm{aq}) / \mathrm{k}(\mathrm{gas})=\exp \left[-\Delta \mathrm{G}_{\text {hyd }}(\dagger)+\Delta \mathrm{G}_{\text {hyd }}(\mathrm{H})+\Delta \mathrm{G}_{\text {hyd }}(\mathrm{Bz})\right]
$$

For the particular case of the benzene addition reaction, the transition state and benzene itself are very similar in size and shape; the solution/gas phase rate ratio reduces to $\exp \left[\Delta \mathrm{G}_{\mathrm{hyd}}(\mathrm{H})\right]$, which is nothing more than the (inverse) Ostwald solubility coefficient for the hydrophobic $\mathrm{H}$ atom. Based on the near equivalence of $\mathrm{H}$ and $\mathrm{H}_{2}$ polarizability and size, and their necessarily similar solubilities, it was demonstrated that the solvent rate enhancement and the curvature in the Arrhenius plot stem almost entirely from the free energy associated with collapse of the $\mathrm{H}$-atom hydrophobic solvation shell. That is, the "hydrophobic attraction" of the $\mathrm{H}$ and benzene in water induces many more attempts of the barrier crossing, and a correspondingly larger rate constant. The implication is that a given $\mathrm{H}$-atom reaction should be 30 to 40 times faster in water than in the gas phase, if specific solvation effects are not important. However, the solvent rate enhancement is much smaller $(\mathrm{k}(\mathrm{aq}) / \mathrm{k}(\mathrm{gas}) \cong 3.7)$ for the light muonium atom $\left(\mu^{+} \ldots \mathrm{e}-\right)$, which can be formed from a positive muon and electron at some highenergy accelerator facilities. The muonium atom acts chemically as an isotope of hydrogen, one ninth the mass of the normal $\mathrm{H}$ atom. Although the hydrophobic attraction between the muonium atom and benzene should still be present, theory and experiment suggest that the large quantum mechanical tunneling component present in the gas phase reaction is quenched in the liquid. 
An interesting contrast to the benzene reaction is the reaction of $\mathrm{H}$ with methanol, which produces $\mathrm{H}_{2}$ and the $\cdot \mathrm{CH}_{2} \mathrm{OH}$ radical as products. Naively, one might predict a similar solvent rate enhancement for the $\mathrm{H}$ reaction with methanol, where a hydrophobic "attraction" to the methyl group can be expected. However, no enhancement is found. At room temperature, the gas phase reaction rate is $2.3 \times 10^{6} \mathrm{M}^{-1} \mathrm{sec}^{-1}$ compared with the aqueous rate of $2.84 \times 10^{6} \mathrm{M}^{-1} \mathrm{sec}^{-1}$ found in this study. The liquid phase activation energy is $6.5 \mathrm{~kJ} / \mathrm{mole}$ larger than the gas phase result. One could argue that the water will solvate the transition state differently from the methanol, so that the aqueous activation energy is different from the gas phase. However, it has also been shown that quantum mechanical tunneling is very important for this reaction in the gas phase. As for the muonium/benzene case, removal of the gas phase tunneling by solvent "friction" effects would counteract the hydrophobic attraction effect and also yield a somewhat higher activation energy.

One of the most interesting results obtained to date involves the $\mathrm{H}$ atom reaction with periodate and periodic acid. The rates for these reactions are needed to help model the spread of radioactive iodine following a Chernobyl-type accident. Several hydration equilibria are involved in describing the actual species present in aqueous solutions of periodic acid:

$$
\begin{aligned}
& \mathrm{H}_{5} \mathrm{IO}_{6} \rightleftharpoons \mathrm{H}_{4} \mathrm{IO}_{6}^{-}+\mathrm{H}^{+} \\
& \mathrm{H}_{4} \mathrm{IO}_{6}^{-} \rightleftharpoons \mathrm{H}_{3} \mathrm{IO}_{6}=+\mathrm{H}^{+} \\
& \mathrm{H}_{4} \mathrm{IO}_{6}=2 \mathrm{H}_{2} \mathrm{O}+\mathrm{IO}_{4}^{-}
\end{aligned}
$$

Because the several species have distinct absorption spectra, the equilibrium constants have been worked out over a large temperature range. Figure 3 shows an Arrhenius plot of results obtained for $\mathrm{H}$ atom reaction with the $\mathrm{IO}_{4}$ - and $\mathrm{H}_{5} \mathrm{IO}_{6}$ species, which we believe results in an $\mathrm{OH}$ radical and reduced iodate product:

$$
\begin{aligned}
& \mathrm{H} \cdot+\mathrm{IO}_{4-}^{-}=\cdot \mathrm{OH}+\mathrm{IO}_{3^{-}} \\
& \mathrm{H} \cdot+\mathrm{H}_{5} \mathrm{IO}_{6}=\cdot \mathrm{OH}+\mathrm{IO}_{3}^{-}+\mathrm{H}^{+}+2 \mathrm{H}_{2} \mathrm{O}
\end{aligned}
$$

Reaction (4) shows a "normal" activation energy of $22.3 \mathrm{~kJ} / \mathrm{mole}$, but reaction (5) has a large activation energy of $59.8 \mathrm{~kJ} / \mathrm{mole}$, which is compensated by an extremely large (possibly a record!) preexponential factor of $6.4 \times 10^{18} \mathrm{M}^{-1} \mathrm{sec}^{-1}$. If we invoke the transition state theory, we can write the 